\title{
Commentary Statin research in critical illness: hampered by poor trial design?
} Marius Terblanche ${ }^{1}$ and Neill KJ Adhikari ${ }^{2}$

\author{
1Department of Critical Care Medicine, Guy's and St Thomas' NHS Foundation Trust, London, UK \\ 2Department of Critical Care Medicine, Sunnybrook Health Sciences Centre \& University of Toronto, Toronto, Ontario, Canada
}

Correspondence to: Marius Terblanche, Marius.terblanche@gstt.nhs.uk

See related research by Morgan et al., http://ccforum.com/content/13/5/R165

Published: 11 December 2009

Critical Care 2009, 13:1015 (doi:10.1186/cc8173)

This article is online at http://ccforum.com/content/13/6/1015

(c) 2009 BioMed Central Ltd

\begin{abstract}
Statin therapy may prevent an excessive inflammatory response after cardiopulmonary bypass for cardiac surgery. In a recent issue of Critical Care, Morgan and colleagues present data from a wellconducted systematic review and meta-analysis of randomised controlled trials using inflammatory markers as primary outcome measure. They find that pre-operative statin therapy, compared with placebo, may reduce various post-operative markers of systemic inflammation (IL-6, IL-8, C-reactive protein, tumour necrosis factor-alpha). Their ability to make definitive conclusions is limited, however, by the suboptimal methodological quality of the primary studies. Their review suggests that ICU researchers should focus on developing valid surrogate markers and use these to accurately describe the mechanisms and effectiveness of novel therapies before proceeding to large pragmatic trials using mortality as primary outcome.
\end{abstract}

In a recent issue of Critical Care, Morgan and colleagues present the results of a well-conducted systematic review and meta-analysis of the effect of statin therapy on inflammatory markers after cardiac surgery [1]. Observational evidence suggests that statin therapy may dampen the inflammatory response following exposure to a significant trigger and there is currently much interest in using statins to treat sepsis $[2,3]$. In this context cardiopulmonary bypass (CPB) is appealing methodologically because it allows the study of preventive interventions [4-6]. Fortunately for patients, mortality following CPB is low, but the methodological downside of this success is that very large trials of low risk patients (or somewhat smaller trials of higher risk patients) are needed to show a mortality effect.

The randomised controlled trials included by Morgan and colleagues measured post-operative inflammatory markers in adults receiving a statin or placebo prior to CPB. They found that statin therapy may reduce post-CPB inflammation as measured by IL-6, IL-8, C-reactive protein and tumour necrosis factor-alpha.

The studies included were generally of suboptimal methodological quality. For example, six of the eight apparently randomised studies provide no information on sequence generation and allocation concealment. Three were unblinded and only two had a low risk of bias (defined by applying the Cochrane risk of bias tool). The median sample size was 43.5 (range 20 to 200) and the confidence intervals around the mean differences in inflammatory markers for individual studies and for the summary estimates were fairly wide. Other studies of inflammatory biomarkers are likely to vary widely between patients and within patients over time, suggesting that analysis of within-patient changes over time may detect differences between treatment groups with more statistical power.

While the meta-analysis does not provide a definitive answer, it raises key methodological issues relevant to sepsis research in general, and to statin research in critical illness in particular.

\section{Failure of sepsis studies}

The sepsis literature is littered with failed trials of pharmacological interventions $[7,8]$. In many instances an initial study demonstrating benefit was contradicted by subsequent work [9]. The methodological quality of many of these studies is variable and frequently the mechanisms (at both biological and functional levels) through which benefit are supposed to accrue were not robustly described [10]. We agree with other authors [8] that the logical sequence of questions to answer before performing pragmatic mortality trials should be: first, can statins theoretically beneficially modulate the immune response in these patient populations? Is it biologi-

$\mathrm{CPB}=$ cardiopulmonary bypass; $\mathrm{IL}=$ interleukin. 
cally plausible? Second, do statins beneficially (and safely) modulate the immune response and associated physiology? Third, does the modulated immune response translate into benefit at the level of organ function?

In this regard the critical care research community can learn much from colleagues in rheumatology, cardiology and oncology, who have explored and described mechanistic pathways - paths reliably connecting biological plausibility and effect with organ performance and then outcomes important to patients (for example, mortality) [11]; and developed reliable and validated surrogate endpoints [11].

Morgan and colleagues want to establish whether potential surrogate endpoints (inflammatory markers) are modulated, but herein lay the problems. First, no validated surrogate endpoints exist for use in critical illness. Second, while data from successful 'mortality' randomised controlled trials may improve our understanding of surrogate outcomes, interventions that improve surrogate markers do not necessarily translate into improved mortality [12-14]. Third, what is the minimum clinically important difference for a biomarker or combination of biomarkers? How much should individual (and aggregate) marker levels differ between groups to translate into clinical benefit? Lastly, what if 'good' markers are also suppressed and, indeed, how much inflammation is good for you?

We suggest these issues are important for the following reasons. It is clear that in this relatively new study area the knowledge space is already occupied by poor studies and potentially unreliable data. We would like to encourage investigators to design studies that are methodologically robust and provide reliable mechanistic data. ICU researchers should work towards developing valid surrogate endpoints to allow robust and reliable translational research, although we acknowledge that previous success at improving organ performance has not always improved outcomes [12-14]. Once validated, these surrogate endpoints should be used to establish the biological effectiveness of new treatments (and probably some existing ones) before moving on to pragmatic studies using mortality as outcome measure [15].

Without demonstrating first biological and then functional (for example, organ performance) effectiveness, we run the risk of wrongly adding statins to the wasteland of ICU pharmacotherapy. On the positive side, the pleiotropic effects of statins and extensive experience with these agents in cardiology mean that we may be less likely to fall into a trap constructed of an insufficient understating of mechanisms combined with a single-target therapy [2].

\section{Competing interests:}

None of the authors have any potential financial or nonfinancial competing interests.

\section{References}

1. Morgan C, Zappitelli M, Gill P: Statin prophylaxis and inflammatory mediators following cardiopulmonay bypass: a systematic review. Crit Care 2009, 13:R165.

2. Terblanche M, Almog Y, Rosenson RS, Smith TS, Hackam DG: Statins and sepsis: multiple modifications at multiple levels. Lancet Infect Dis 2007, 7:358-368.

3. Terblanche M, Almog Y, Rosenson RS, Smith TS, Hackam DG: Statins: panacea for sepsis? Lancet Infect Dis 2006, 6:242248.

4. Terblanche M, Smith TS, Adhikari NK: Statins, bugs and prophylaxis: intriguing possibilities. Crit Care 2006, 10:168.

5. Ridker PM, Rifai N, Clearfield M, Downs JR, Weis SE, Miles JS, Gotto AM Jr: Measurement of C-reactive protein for the targeting of statin therapy in the primary prevention of acute coronary events. $N$ Engl J Med 2001, 344:1959-1965.

6. Ridker PM, Rifai N, Pfeffer MA, Sacks FM, Moye LA, Goldman S, Flaker GC, Braunwald E: Inflammation, pravastatin, and the risk of coronary events after myocardial infarction in patients with average cholesterol levels. Cholesterol and Recurrent Events (CARE) Investigators. Circulation 1998, 98:839-844.

7. Marshall JC: Clinical trials of mediator-directed therapy in sepsis: what have we learned? Intensive Care Med 2000, 26 Suppl 1:S75-83.

8. Marshall JC: Such stuff as dreams are made on: mediatordirected therapy in sepsis. Nat Rev Drug Discov 2003, 2:391405.

9. Sweeney DA, Danner RL, Eichacker PQ, Natanson C: Once is not enough: clinical trials in sepsis. Intensive Care Med 2008, 34:1955-1960.

10. Annane $\mathrm{D}$ : Improving clinical trials in the critically ill: unique challenge - sepsis. Crit Care Med 2009, 37:S117-128.

11. Bucher HC, Guyatt GH, Cook DJ, Holbrook A, McAlister FA: Users' guides to the medical literature: XIX. Applying clinical trial results. A. How to use an article measuring the effect of an intervention on surrogate end points. Evidence-Based Medicine Working Group. JAMA 1999, 282:771-778.

12. López A, Lorente JA, Steingrub J, Bakker J, McLuckie A, Willatts S, Brockway M, Anzueto A, Holzapfel L, Breen D, Silverman MS, Takala J, Donaldson J, Arneson C, Grove G, Grossman S, Grover R: Multiple-center, randomized, placebo-controlled, doubleblind study of the nitric oxide synthase inhibitor 546C88: effect on survival in patients with septic shock. Crit Care Med 2004, 32:21-30.

13. Watson D, Grover R, Anzueto A, Lorente J, Smithies M, Bellomo R, Guntupalli K, Grossman S, Donaldson J, Le Gall JR: Cardiovascular effects of the nitric oxide synthase inhibitor NGmethyl-L-arginine hydrochloride $(546 \mathrm{C} 88)$ in patients with septic shock: results of a randomized, double-blind, placebocontrolled multicenter study (study no. 144-002). Crit Care Med 2004, 32:13-20.

14. Bakker J, Grover R, McLuckie A, Holzapfel L, Andersson J, Lodato R, Watson D, Grossman S, Donaldson J, Takala J: Administration of the nitric oxide synthase inhibitor NG-methyl-L-arginine hydrochloride $(546 \mathrm{C} 88$ ) by intravenous infusion for up to 72 hours can promote the resolution of shock in patients with severe sepsis: results of a randomized, double-blind, placebo-controlled multicenter study (study no. 144-002). Crit Care Med 2004, 32:1-12.

15. Marshall JC, Vincent JL, Guyatt G, Angus DC, Abraham E, Bernard G, Bombardier C, Calandra T, Jorgensen HS, Sylvester $\mathrm{R}$, Boers M: Outcome measures for clinical research in sepsis: a report of the 2nd Cambridge Colloquium of the International Sepsis Forum. Crit Care Med 2005, 33:1708-1716. 